\title{
THE INVESTIGATION OF MENTAL DISORDER BY ELECTRO-ENCEPHALOGRAPHY*
}

\author{
Major P. ABRAHAM, M.R.C.S., L.R.C.P., D.P.M:, D.T.M.\&H., R.A.M.C. \\ Royal Victoria Hospital, Netleyt
}

SUMMARY: The application of an electro-encephalographic technique to the investigation of mental disorder is described. It is hoped not only to gain a better insight into the nature of mental disorder and possibly the mode of action of psychotropic drugs, but also to devise procedures which can be of practical value in the diagnosis and management of these conditions.

\section{Introduction}

The conventional electro-encephalogram (e.e.g.)

When electrodes are placed on the skin of a subject minute potential differences between them can be continuously recorded, resulting in an electrocardiogram, nystagmogram, or myogram, depending on where the electrodes are placed. If one of the electrodes is placed over the precordium the recording shows a constantly repeated pattern. Reliable conclusions can be drawn about the position and condition of the heart which is the source of the electrical activity represented by this pattern. If the electrodes are placed on the scalp, the electrical activity of the brain results in a recording which is anything but regular (except during petit mal discharges). Despite, this occasionally, with experience and good fortune, the recording may enable one to deduce the presence of some physical abnormality such as a subdural haematoma, and to localize it correctly. Generally speaking, however, one may only draw the vaguest conclusions about the subject's mental state such as that he is 'asleep' or 'concentrating', and practically none about the presence or nature of a mental disorder.

\section{Evoked responses}

If the subject is presented with a stimulus, such as a flash of light, repeated at random time intervals, a tiny cortical response as constant as that of the e.c.g. occurs but is lost in the 'sea' of irregular e.e.g. waves. But if every time the stimulus is presented the fluctuations in potential are recorded for one second and these one-second strips are added together (most conveniently with a computer), the irregular fluctuations tend to cancel each other out and the constant evoked response stands out more and more clearly. This technique has opened up a vast field of research and clinical uses, such as the investigation of deafness in unco-operative subjects like young children or malingerers.

\section{The Contingent Negative Variation}

In 1964 Grey Walter reported that whereas paired sti muli such as clicks and flashes merely produced two separate and different evoked responses, a remarkable phenomenon occurred if in response to the second stimulus the subject was required to participate by

* Based on a talk given to the Brain Research Association at King's College, Cambridge on Tuesday 16th July 1970.

$\uparrow$ Now at the Military Hospital, Catterick. 
pressing a button. Between the two evoked responses there was a slow build-up of negative potential which died away abruptly as soon as the decision to press the button was made. This became known as the Contingent Negative Variation (C.N.V.), is remarkably constant in form for a given individual, and as far as can be judged from the research up till now is associated with purely mental activity: anticipating pressing the button and deciding to do so.

\section{The investigation of mental disorder using the C.N.V.}

Cheyne McCallum (1966) working with Grey Walter at the Burden Neurological Institute took the matter a stage further by noting that a group of psychopaths hardly developed a C.N.V. at all. McCallum also noted (McCallum and Walter, 1968) that if between the presentation of the paired stimuli a simple distraction in the form of morselike sounds was introduced, the magnitude of the C.N.V. was significantly reduced, while that of subjects with mental disorder, such as pathological anxiety and more especially schizophrenia, almost disappeared. More recently a group working in Liege (Timsit et al, 1968 and 1970) reported that the C.N.V's of schizophrenics frequently did not die away abruptly when they responded to the second of the paired stimuli, particularly if their C.N.V. was large initially. The Burden workers also noticed, but have not yet established, that the C.N.V's of schizophrenics are less constant in form and amplitude than those of other subjects.

The study of the C.N.V. thus offers a means both of identifying, and gaining insight into the nature of, mental disorder.

\section{Difficulties in studying mental disorder}

Most of the studies of mental disorder so far have suffered from two grave problems. Firstly, the patients have almost invariably received some medication and it would be indefensible to deprive them of this for experimental purposes. In such a study one cannot be sure therefore that one is not measuring the effects, either immediate or long term, of the drugs, on the mental state or the whole organism. In the case of chemical analysis of body fluids, one may even be measuring the drug itself or its breakdown products. In the Services a patient who develops an acute psychotic illness tends to be hospitalized early and rapidly. One may therefore be able to make measurements on quite disturbed patients before treatment has begun. This advantage has already been put to good use at the Royal Victoria Hospital (R.V.H.), Netley in the study of biologically active peptides extracted from the urine of patients. One of these peptides appears to be present in significantly greater quantity in patients who have schizophrenic symptoms.

Here we come to the second big problem in the study of mental disorders generally, and of their physical manifestations in particular, and that is the definition of the disorder to be studied. Psychiatrists have not yet decided on a working definition of 'schizophrenia' and can do little better than describe a group of related syndromes which they come across frequently in varying forms amongst their patients. Two psychiatrists in the same hospital will often disagree on the precise diagnostic category to which to assign a given patient, and as one crosses national boundaries the divergence grows wider. In one study sarried out recently patient $F$ was described as schizophrenic by 69 per cent of the United States psychiatrists taking part. Only 2 per cent of the United Kingdom psychiatrists, using the same (videotaped) interview, chose this diagnostic label for patient F. In other 
words if we cannot accurately define the disorder and determine which of our subjects is suffering from it and to what degree, our meticulous measurements of the physical concomitants of the condition become valueless.

A group based at the Maudsley Hospital has devised an elaborate technique for examining the current mental state of a patient which is highly reliable, when applied by experienced psychiatrists trained by them to apply their standards and methods faithfully (Wing et al, 1967, Kendell et al, 1968). Correlations of greater than 0:9 have consistently been obtained between the scores of different clinicians rating symptoms and groups of symptoms presented by the same patient in one interview, and slightly lower correlations when there were separate interviews. On the basis of these assessments it was possible for the clinicians to allocate the patients to their diagnostic categories with a high degree of agreement. This technique has been used to show that the apparent differences in incidence of schizophrenia and depression in young males in New York and London was in fact due to differences in diagnostic labelling (Cross National Study, 1969). Without the use of such a technique the study of C.N.V. impairment in psychotic young males would almost certainly yield different results on either side of the Atlantic.

\section{Method}

The present work at R.V.H., Netley

In the current programme a newly hospitalized and untreated serviceman whom the consultant considers is suffering from a schizophrenic illness starts collecting a twentyfour-hour specimen of urine which is extracted and assayed for the biologically active peptides referred to above. During that twenty-four-hour period a standardized recording of the C.N.V. is made and subsequently analysed at the Burden Institute. Finally the patient is examined according to the 8th Edition of the Present State Examination used at the Medical Research Council, Social Psychiatry Research Unit, at the Maudsley Hospital.

The C.N.V. is recorded again a week later in a rough attempt to assess the influence of treatment alone, and the C.N.V. recording and Present State Examination repeated shortly before the patient is due for discharge in an attempt to discover any difference which might be attributable to his improved clinical state. The duration of the Spiral After Effect is measured on each occasion. Single members of the staff, living in the hospital and receiving a diet similar to that of the patients, form a control group. The same set of tests including the Present State Examination is carried out with them, but they do not of course receive treatment.

\section{Aims}

To establish the characteristic C.N.V. features of schizophrenic disorders in untreated patients whose normal mental state has been determined by a reliable, standardized procedure in order to overcome the two difficulties pointed out in this paper.

To apply the same principles to the analysis of the urinary peptides in the same patients to discover whether the activity of these compounds is in fact related to the mental state as determined by clinical and electrophysiological means.

To determine the relationship of the e.e.g., the C.N.V. and biochemical variables, not so much with diagnostic categories as with groups of symptoms (such as obsessional/ 
compulsive symptoms) and single symptoms (such as Schneider's ' first-rank' symptoms) in order to discover whether these variables correlate with the characteristic features of schizophrenic disorders, not, merely incidental aspects of them such as the anxiety which both schizophrenics and depressives often suffer.

These could be steps towards an understanding of the neurophysiological and neuropharmacological processes underlying schizophrenic disorders and their treatment, as well as towards the development of diagnostic aids.

\section{Results}

The data which we have so far do not justify any firm conclusions but do indicate the sort of results we might expect to find. For instance those patients who have any Schneider's 'first-rank' symptoms differ significantly from the symptom-free control subjects, not only in having C.N.V's which are of lower voltage with auditory distraction, but also in having a lower voltage C.N.V. in the first place, and in having urinary peptides with a stronger inhibitory action on the oxidation of 5 -hydroxytryptamine. The values of these variables obtained in patients who do not have any 'first-rank' symptoms seem to approximate more closely to those found in the control group. The amplitude of the C.N.V. in the distraction condition seems to differentiate the definitely schizophrenic group from the control group regardless of whether the measurements are made before or after a prolonged course of treatment, provided that the schizophrenics are currently experiencing ' first-rank' symptoms.

It is intended to report a full account of this electro-encephalographic investigation of mental disorder with Doctor Cheyne McCallum at a later date. Meanwhile, thanks are due to all those who are assisting with the present work.

\section{REFERENCES}

Barrass, B. C., Coult, D. B., Drysdale, A. C. and Marjot, D. H. (1970). Inhibition and activation of caeruloplasmin by extracts from the urine of schizophrenic patients. Biochem. Pharmacol. $19,1674$.

Cross-National Study of Diagnosis of the Mental Disorders. (1969). Suppl. to Amer. J. Psychiat. $125,10$.

Drysdale, A. C., Wawman, R. J. and Marıot, D. H. (1969). A toxic fraction in the urine of schizophrenics. J. roy. Army med. Cps. 115, 380.

Kendell, R. E., Eyerett, B., Cooper, J. E., SARtorius, N. and David, M. E. (1968). The reliability of the Present State Examination. Soc. Psychiat. 3, 123.

McCallum, W. C. (1966). The E.E.G.: Has it a Future in Social and Clinical Psychology? Proc. Univ. of Lond. Psychol. Soc. Nat. Psychol. Conference. London.

MCCAllum, W. C. and WALTER, W. G. (1968). The effects of attention and distraction on the contingent negative variation in normal and neurotic subjects. Electroenceph. Clin. Neurophysiol. 25, 319.

Timsit, M., Koninckz, N., Dargent, J., Fontaine, O. et Dongier, M. (1968). Etude de la variation contingente negative chez les pre'-psychotiques. Ann. Med. psychol. 1, 3, 424.

Timsit, M., Koninckz, N., Dargent, J., Fontaine, O, et Dongier, M. (1970). Variations contingents negatives en psychiatrie. Electroenceph. Clin. Neurophysiol. 28, 41.

Walter, W. G., Aldridge, V. J., Cooper, R., McCallum, W. C. et Cohen, J. (1964), L'Origine et la signification de l'onde d'expectative. Rev, neuro!. 111, 257.

Wing, J. K., Biriey, J. L. T., CoOper, J. E., Graham, P. and IsAacs, A. D. (1967). Reliability of a procedure for measuring and classifying " Present Psychiatric State". Brit. J. Psychiat. 113, 499. 